clinic staff text "Mambo?" ("How are you?") in Kiswahili. The "WelTel" trial was published in The Lancet in 2010, and this year Lester received \$2 million to scale up across rural Kenya.

Labs on chips: The idea of a lab-on-achip — automated chemical analysis using microfluidics to measure a droplet of spit or a pinprick of blood in a space smaller than 1 square millimeter — was first described in 1990, but development has proven difficult. The potential for low-income countries is enormous says James Fraser of ChipCare, a University of Toronto engineering spin-off working on a hand-held blood analyzer that health workers could use to do CD4 counts required for ongoing AIDS treatment.
Like other global health innovators, ChipCare engineers are Grand Challenges Canada beneficiaries, raising over \$2 million last year from Grand Challenges and other investors, but the road from the lab to the village could still be long. Miriam Shuchman, Toronto, Ont.

CMAJ 2014. DOI:10.1503/cmaj.109-486

\title{
New residency program for pain specialists
}

$\mathrm{R}$ oughly one-quarter of Canadians suffer from some degree of chronic pain, and for those over the age of 60 , the figure is closer to $50 \%$. But according to Dr. Pat MorleyForster, a professor in the department of anesthesiology and perioperative medicine at Western University in London, Ont., most practitioners' training focused almost entirely on acute, not chronic pain.

Now, after almost a decade of planning, Western has launched Canada's first residency program in pain management. "We were able to demonstrate that there was a wealth of knowledge out there about how to treat pain that was not being taught to doctors. This unmet need would take two full years of doctor training," said Morley-Forster, who is also the chair of the special committee on pain management at the Royal College of Physicians and Surgeons of Canada.

The program at Western is modelled after similar ones that have been operating in Australia since 1999 and the United Kingdom since 2002. Residents can access the subspecialty program through prior certification in anesthesia, neurology, psychiatry, physical and rehabilitative medicine, palliative care, rheumatology, pediatrics or emergency medicine.

Residents will complete 12 onemonth rotations in a multidisciplinary clinic, compulsory rotations in psychiatry, with an emphasis on addiction medicine, and rotations in pediatric, cancer and acute pain.

"A resident may decide not to specialize in chronic pain, but will instead select cancer pain, or chronic non-cancer pain. The program is open-ended enough that residents can pick up that

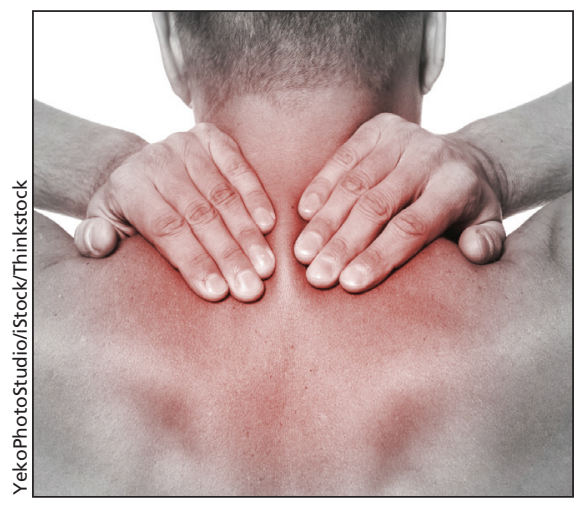

The Canadian program is modelled after similar ones that have been operating in Australia since 1999 and the UK since 2002.

expertise through their elective studies," Morley-Forster said.

Dr. Barry Death, a physiatrist in a pain clinic at St. Joseph's Health Care London, London, Ont. endorses the residency program. "Pain behavior is very complex. ... The first step is to have the doctor welltrained to recognize the triggers."

Unfortunately, he added, few insurance programs will completely cover services for occupational therapists and physiotherapists, or for social workers and psychologists, all of whom should be part of the interdisciplinary pain management mix. Doctors who complete this residency program could find themselves working in clinics where the emphasis is on writing prescriptions and offering injections rather than delving into the nonpathological causes of the patient's pain.

"Medicine in Canada still funds interventions and technologies better than it does talking to patients," he said.

Although more training in pain management would be a positive step for the profession and patients, the Canadian Medical Protective Associa- tion (CMPA) warns that there could be risks involved for physicians who deal in pain management.

Dr. Kathryn Reducka, physician risk manager with the CMPA, recently discussed the medicolegal risks in the management of chronic pain in a presentation at Western University. She didn't answer specific questions, but in an email said opioid use continues to be a serious concern. She referred to a report showing that from 2000 to 2009 , the CMPA defended 49 lawsuits where a physician legitimately prescribed opioids that led to some form of adverse event for the patient. This represents only "a slice" of the picture, she said, since it only refers to cases where legal action was launched.

She also cited a 2009 CMAJ article by Dhalla and colleagues, showing that, in Ontario alone, opioid-related deaths doubled from 1991 to 2004. Since longacting oxycodone was added to the provincial formulary in 2000 , there has been a $41 \%$ increase in overall opioidrelated deaths.

"The reality of practice is that there are limited physician human resources, and physicians are often asked to provide care they may not be totally comfortable providing," Reducka stated.

Morley-Forster predicted that within five years, every province will have at least one university offering a subspecialty residency in pain management. However, none of the provincial health ministries has earmarked funding for any new residency programs. Operating costs will have to be siphoned off from existing programs to support the new areas of specialization. - Cameron Johnston, London, Ont. 